\title{
Symbolic Deterritorialization: The Case of Gabriel Orozco
}

\author{
Jesús Segura Cabañero \\ Department of Fine Arts, University of Murcia, Murcia, Spain \\ Email: jesusegu@um.es
}

Received 12 January 2015; accepted 26 January 2015; published 5 February 2015

Copyright (C 2015 by author and Scientific Research Publishing Inc.

This work is licensed under the Creative Commons Attribution International License (CC BY). http://creativecommons.org/licenses/by/4.0/

(c) (i) Open Access

\begin{abstract}
In a global context the artistic production has developed its critical processes from the inclusion and participation of audience in the works of art. Somehow the expansion and compression of space-time is reflected in the characteristics of many artists whose work is based on the occupying, mapping and reinterpreting of the spaces that they appropriate. This article tries to analyze the spatial and temporal turn defined by the works of artist Gabriel Orozco, The individual and collective memories, spaces of history, politics and culture are signified by the act of symbolic deterritorialization and reterritorialization. The article also analysed the phenomenological and material treatment of objects of Gabriel Orozco in his temporal frequency and perceptual reinterpretation in the context of cultural and political globalization in order to confront symbolic deterritorialization as a resource of his artistic production.
\end{abstract}

\section{Keywords}

Space, Time, Deterritorialization, Symbolic, Gabriel Orozco

\section{Introduction}

The aim of this essay is to map and reveal the questions about the construction of historical time of modernity and confront it with memory formation arising in a system of heterochronic equivalences or what Andreas Huyssen (2002) has called "the memory turn". These global memories are configured using multiple equivalences governed by ambivalence whose bases are held, as Arjun Appadurai (2001) argue in a negotiation between the historical and the social, the affects and the politics, and between the global and the local. Many artists explore these issues in their symbolic process about the idea of making conteporary art today. In a way in which a whole "symbolic displacement of territories" is put into play.

This is the case of artist Gabriel Orozco although widely referenced have become pioneers of this memorialist 
frequency of symbolic order. Now, far from the actuality of his work, when it seems more appropriate to set the importance of symbolic production processes involved in their production in order to understand the new displacement of the symbolic in the actual movements.

Gabriel Orozco, begin with found objects, which transforms in the middle of the conscious action of a subject who has lost their home territory and tries to find it in the places where they live. Orozco is a nomadic artist without belonging. The artist produced most of his work on the move with his displacement; any territory has meaning, he specifies it, collects it and finally he show the sample.

The presence of multiple traces of time in the world around us is a revelation that he is interested to trap and become a referent of a visual language, where matter is the vehicle of an idea and not an end in itself. His works are formed in the interaction with living spaces. And the temporalities that displays are shown in a dialectic heterochronics subjugated to a monochronic temporality that embody the processes of production and consumption. That is, Orozco believes that cultural symbols are traps, and their transgression is given by temporary erosion in a micro and macro level depending on the displacement of the symbolic, and the cycles of production and consumption thereof. In this sense, his works subvert a state of production of goods and consumer fetishes, and establish a dialectics of production on the sculptural object.

\section{The Phenomenology of the Object: Mutant Temporalities of the Symbolic Displacement}

Simon Critchley (2010) writing about the work of Philip Parreno, suggests a renewed attention to things through singularization processes that constitute its mineral quality, in its pure materiality in order to emerge an autonomy of the event that is detached from our will and enters in an anarchic and non authoritarian parameters. However, as he points out display an ataraxia far from the mysticism, which updates the observation of material details in course to return the author's authority to the contingent materiality of nature. This obviously leads into another order of time.The presence of multiple traces of time in the world around us represents a revelation that Orozco wants to catch and become referent of a visual language, where matter is the vehicle of an idea and not an end in itself. His works are formed in the interaction with living spaces:

“(...) Villages of everyday objects, a dump, a crack in the sidewalk, a pool, a light, a collection of waste likely to be found in any city in the world. In his travels, the artist captures images, which later are transformed into a sculpture, an installation, a photograph or drawing” (Bonami, 2002).

The artist appropriates realities seemingly insignificant to give them significance in playing with the settings between the everyday and contemplation. All this becomes an intellectual process that is particularly disturbing, engaging and transformative, as mentioned by Orozco himself: "The important art regenerates the perception of reality, enriches and transforms it” (Bois et al., 2007: p. 16). The association that makes Orozco with the body and the spatiality is manifested in the dialogue of matter with space. Thus, in his work we find unusual and poetic interpretation of the everyday without losing sight of political consciousness subjugated to production processes. The close link of the artist with nature and with those objects inhabited by a cultural, political and social burden, from the human intervention led him to set up a work where mobility and memory is crucial in this process.

Orozco loves the idea of movement, perpetual displacement. Hence the stubborn accumulation of spherical bodies, that rolled back to a unit, a whole. This derives in his interest in nature as a perfect structure that devours and engulfs the human convection. Through nature he makes a permanent working strategy, where development from a physical centre, gives way to packaging and containers. The break with idealism in which Orozco submits nature leads him to articulate a conception of this; where the duality natural-artificial oversees all his conceptual purposes. So the meanings between the natural and the artificial in Orozco's work intersect to form figures with a transition between the language and the phenomenon. His reflections on the three-dimensional works lead him to pose the works where the movement, speed, gravity shape their approach, or rather, their questions about the matter, materials as structural facts. Where its topography and formal structure gives knowledge of the object itself. In an interview with Briony Fer says:

"The centre of gravity has always been very important to me (...) centre is the backbone of the body, is the centre of gravity that connects the body with the earth (...) this explains why the sphere or circle are the best way for me to show the points of gravity and vanishing (...) The three-dimensional, 
gravity, motion, light, symmetry, organic, these are things that I deal” (Bois et al., 2007: p. 92).

But the idea of erosion is very present in his work. From a practice that tries to restore the usefulness of the material, Orozco convened a series of intervention tactics where erosion by body pressure, or erosion by natural elements such as wind are configured as organic approaches, where the idea of the seed underlies as a catalyst for the process. In this sense Orozco assumes scientific proposal that proposes a relational space where this is constituted by the interaction of matter and its parts. The implementation strategies employed move between the logical arrangement of space and entropic disorganization, which is under a system of parts. That is to say entropy and geometry. Benjamin H. D. Buchloh said: "What the object have lost first, was apparently its immutable status, its strong promise of producing use value. Now the objects are defined as totally ephemeral, its mere function was to perform temporary work to generate exchange value” (Bois et al., 2007: p. 157).

Indeed, Orozco realizes about this and begins to work within the structure of the object from its centre. Thus crumbles the morphology of the sculptural object and subverts modes of presentation. As noted earlier Orozco's linking with nature and with those inhabited objects by a cultural, political and social burden developed through human intervention, have largely determined the insight into the everyday, to scan the environment and transform it. Thus the use of archaeological processes with the objects involved is no more than semantic processing strategies of the object itself. Where the void gives way to a space setting. The configuration space practiced by Orozco assumes nomadic displacements and is executed through random paths or with an associative order. Orozco makes his actions amidst uprooted territories, which appropriates, generating in them traces and marks in a dialogue context. Orozco appropriates other cultures, other histories, where: “(...) is the artist's cosmopolitan universe, which records aspects of an increasingly homogenous world: The world of migration, the movement of capital and goods, customs equalization and cancellation of differences” (García Canclini, 1997: p. 80).

\section{Spatialities and Overwhelmed Territories}

Orozco is inserted in this contemporary mobile amidst endless chain appropriations and copies that exist in repetition. Orozco is represented in its nomadism, in its particularity of a privileged immigrant-as claimed by the same artist-determined by transition spaces, which explores the poetic strangeness of the object in its contextual dérive. Dwelling in the in-between spaces, which are manifested in constant circulation, like contemporary stocks. As Bhabha (1998) accurately has defined, he rehabilitates that space "in-between" and proposes a third space where it eludes the polarity policies. And working from a representational immersion of the different reconstructive levels of the representation itself, to find the area of discussion that allows us to emerge and build a trans-representational sense.

Orozco's position in the early nineties was skeptical about production systems and distribution of art. So his interventions take the distribution infrastructure as an artistic element, imbuing by the everyday experiencing that generated a real experience. Representation was not important in itself, but the interaction with the object as if it were a phenomenon. This brought an interpretation of the object that has multiple meanings. Not only as a container, as a receptacle, but also as a vehicle itself. In this sense, Orozco recovers the world as a workshop and interacts looking for its ontological dimension, to set aside the pure representation. Of course there is a record that assumes the representation, but has no intention of staying there, because the phenomenological action is still evident beyond the record itself. The representation takes the container-form as registration status, but not as phenomenological essence. Similarly this conceptual significance is taken to space, displacement and mobility of the work, to make new meanings in that transition through erosion that makes new symbolic elements.

But this vehicle has a centre that has been reinvented, reworked for a semiotic expansion of the object. Keep in mind that this growth does not exclude the destruction of the centre. Although Orozco interprets the centre as the backbone and the centre of gravity of the objects that connects the entropic forms that arise. Thus, the attack to the morphology of the object became a tactic to reconfigure the display modes of the object itself and their use values, exchange and exhibition. In short, and as noted by Buchloh, objects become "quintessential anti-fetishes that allow us to glimpse the latent collectively token resistance to total reification, if not to the termination of the relationship between subject and object” (Bois et al., 2007: p. 178).

But the obstinacy of Orozco focuses on recovering the value in use, to regain access to the object without forgetting utilitarian object processes within a social and communicative structure. But he is not willing to give up two fundamental concepts in his work: The game and the organic growth. In this sense, a large part of his work assumes a phenomenological aspect, which makes the object to experience changes in each proposed in- 
tervention, and assumes its organic character. In fact, the notion of organic growth that begins in a centre without knowing how it will end, is one of references in Orozco's work. For example, if we take one of his sculptures La piedra que cede (1992) (Figure 1), this piece is conceived as a:

"soft stone, a ball of clay, also embodies in its shape a kind of space of otherness interpretation. The ball has about the same weight that the artist, the artist in his various trips, rolls the ball through the streets of every city in which it is exposed, making in the soft sculpture discreet changes in its shape and collecting the garbage of the city, tracing imaginary and unstable routes of the traveller through the modern metropolis. This show makes reference to a common shared space: the incommensurable space of immigrants and natives communities that leaves its anonymous marks. This sculpture is also, in its indeterminacy, a pun around saying 'moving stone gathers no moss.' This reference refers to the problem of migration and displacement” (Okwui, 1997: p. 26).

Also Photographs as Aliento sobre piano (1993), gives account about the phenomenological extension embedded in a poetics of disappearance and the phenomenon seen in his pieces. If we take the work Hasta que encuentres otra Schwalbe amarilla (1995), it is observed a procedural action followed by the artist: looking for a motorcycle the same as he owns through the streets of Berlin, then park and take a picture that will collect later. This action indicates in the photographic record of the artist a kind of phenomenological procedure where

"The absence of the figure in space makes the experience of the performance being suspended, and obviously incomplete (...) as a constitutive field that shapes the representative repertoire of the artist (...) And, with an act of repetition or replication as 'original' occasion of its use in the context of experience (...) The replica, will live projected in the progressive development of his work, will live a life of repetition, to the extent that the artist embarks on a self-imitation process” (Okwui, 1997: p. 30).

We must therefore determine that his photographs are not based on an original but from a nomadic situation, as reflected through these repeated situations of search and delimitation of recognition paths. In this sense, identification with the search object is closely related to its morphological and conceptual estrangement. But also with a keen political sense, when it is incorporated a certain homogeneity resulting from globalization in their migratory aspects, whether this flow is of capital and goods, or as some ethnic and aesthetics rationalization. However, there is a kind of game, the game invented by the artist who makes the work flow through rational platforms and baffles the viewer. In a way there is a subversion of the grammars of the game. So when asked by Briony Fer about this regard, Orozco responds:

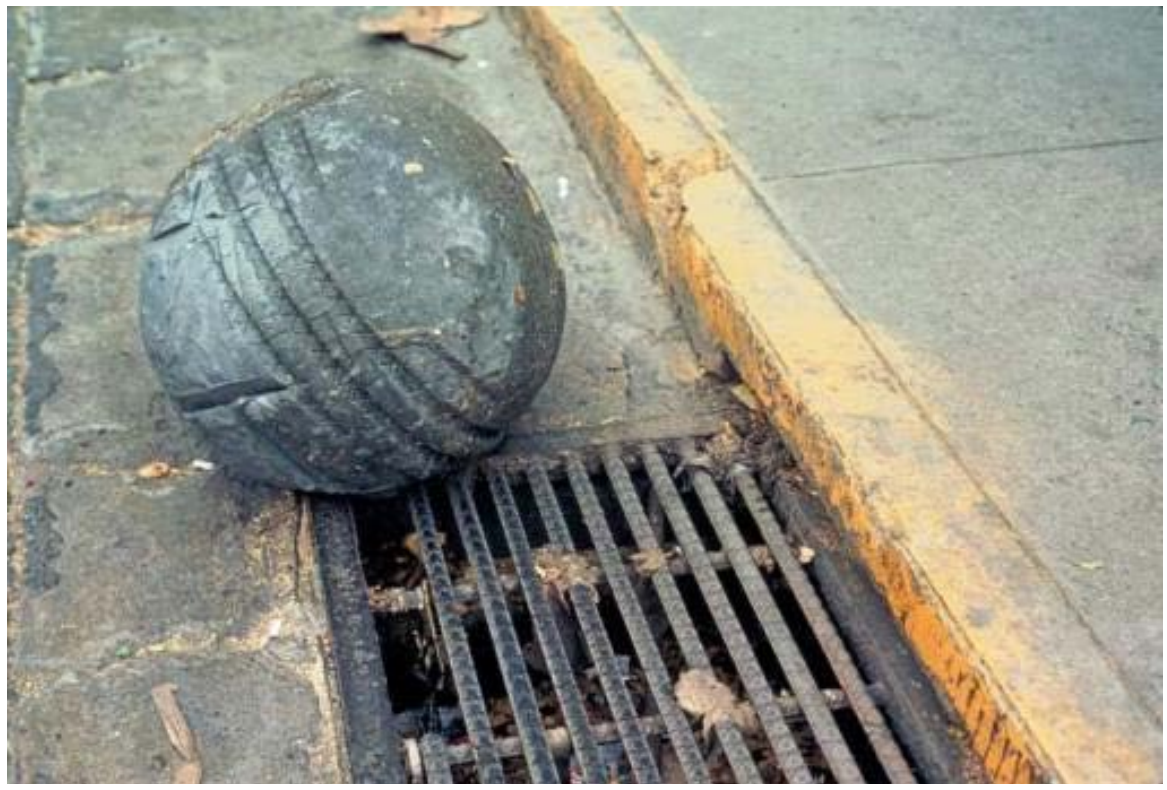

Figure 1. Gabriel Orozco, La piedra que cede, 1992. 
"They were not institutionalized games, but games like those that are invented in a specific situation. When I was a kid I invented games. Those are my favourites, the invented. You adapt a known game to a different court, for example playing volleyball between two cars (...) they are all games I invent with my own rules” (Bois et al., 2007: p. 80).

At another point, concerning the creation of the Cazuelas (2002) explains:

"It was a game between the Baseball and Basketball, trying to make the ball fall inside the pot while turning. It was like a meteor. The exercise was a weeklong. All the time I have been throwing balls against the molds until they formed the casserole. It was a reflection on the erosion, movement, space, planets, and so on. Everything was there” (Bois et al., 2007: p. 119).

Logically, the invention of these "personal” rules he refers brings a conception of confronted assumed concepts. It is a matter of the natural versus artificial and the geometric versus the organic. In Orozco’s own words: “(...) So for me it is not clear what is artificial and what is natural, what is language and what are the phenomena" (Bois et al., 2007: p. 90).

As noted above, obviously the approach of Orozco inevitably involves an awareness of the materials in its structural sense. Thus, the conceptual unevenness that proposes the material itself marks the development and flow of the development of the work. This is why the dialogue that occurs between the artist and the execution of the work is very important in the process of configuring it. The notion of artistic creation as a means of knowledge in Orozco is almost paradigmatic. The very creation of the final product, the object is derived from the process of understanding the object itself through its artistic intervention. An illustrative example is Papalotes Negros (1997). In this sense, the approach to a liberalized production method of production and consumption cycles is due to a "de-creation" (Bois et al., 2007: p. 115). It is based on the concept of a statute of the sculptural object. As Buchloh pointed: “(...) the production, that is the domain of media and materials for centuries had been the epistemic centre of the execution of the sculptural” (Bois et al., 2007: p. 161).

However, the subversion of these procedures in Orozco's work is tremendously hybrid, incorporating elements "halfway" without a defined status. Where the object has been uncharged from its identity as such. This is very clear in its Mesas de Trabajo (1993-1996), since what is presented are often failed “pieces”, which in many cases is neither object nor work, and maintain their status in the process of material becoming the object or final work. This unfinished look is extremely disturbing to the capitalist structure that wants jobs finished with a status defined, pending speculation. Is something in which control is not contained in the tissue of the exchange values that manages the structure of capitalism. Thus we have a crack, a gap that remains active simultaneously the idea of production and denial.

However, the work that I think is crucial in this respect is Proyecto Penske (1998) (Figure 2). Here we have

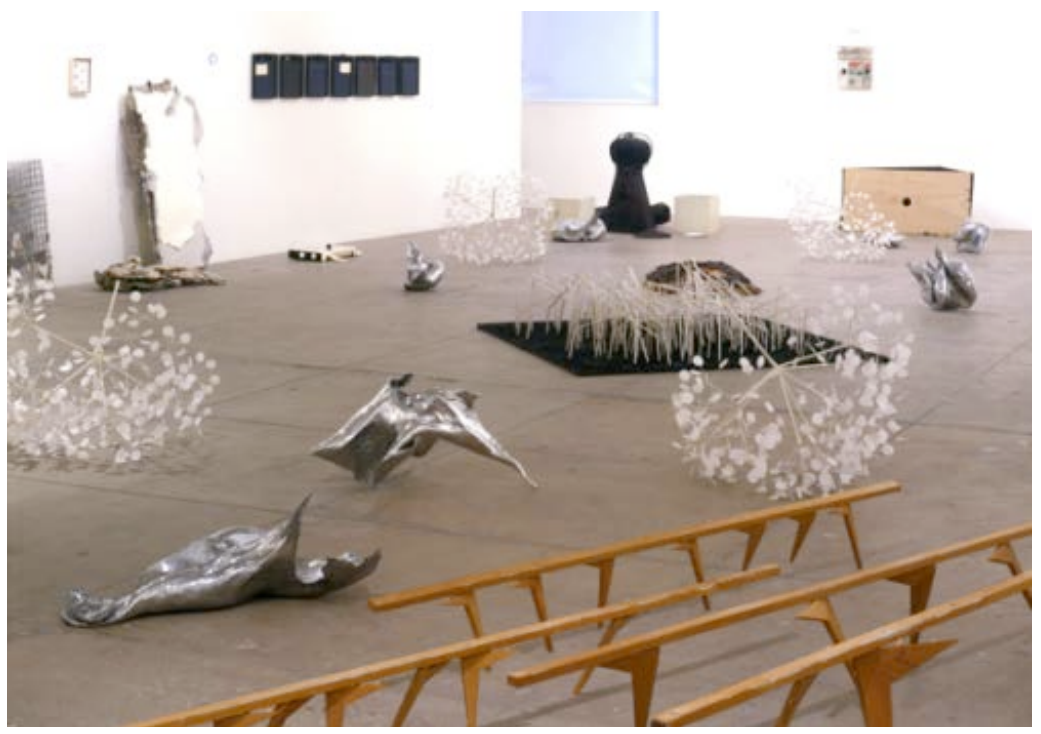

Figure 2. Gabriel Orozco, Proyecto Penske, 1998. 
an action where the artist brings into play many of their des-creative concerns. For Proyecto Penske, Orozco rented a Penske company truck and hung around New York for a month. Stopping then in the dumpsters to collect architectural building materials, making sculptures in situ, and then storing them in the truck he used as a warehouse. At the same time gave a portable space for the work. This is a working process that seeks architectural sculpture dimension represented by detritus, through the ruins, by denying this in public. But it also introduces a reflection between the object and its obsolescence. As Buchloh explains: "The appearance of being tied to what is past, to what has become dysfunctional, to the exhausted object, speaks of a radical turn, at least in some sculptural proposals". And then added about this project: "It is that devotion to redeem materials and objects on their own terms that requires Orozco decision to shorten the transition from use value to exhibition value at the Penske Project” (Bois et al., 2007: p. 115).

Indeed, Orozco performs a garbage collection in New York and moved its unchanged findings to the gallery space. These findings clearly show that transit from the use value to the exhibition value because that "wrapper”, is the mediator "between the use value, exchange value and exhibition value” (Bois et al., 2007: p. 177). But also it is a refusal to provide the experience of the use value because the excess, the detritus, is somehow a waste of the object and therefore a denial of the same as such in its final constitution. There is a phrase in the Orozco workbook, which gives us an idea of his process of work.

"The word art is a verb, such as running, surfing, looking, breathing and eating. The word to do is defined by the action. In that action it is discovered the possibilities of art. Not in the fixed, finished, solved object but in what happened infinitely before. That final object should be the calm of the contained gesture, of the prior gestures that led to its realization” (Bois et al., 2007: p. 206).

\section{Conclusion}

The artist explored here is based on the idea of space and time to set up his artistic articulations and interventions where the fact of mapping and occupying the space symbolically occurs. Orozco mapped spaces of power, contrasting cultural, political and social symbolism with personal memories and cultural perception of the place of origin in which the linguistic and phenomenological process allows symbolic movements.

In spatiotemporal configurations according to David Harvey (1989) the idea of conflict is a continuous process, and there is no grammar, laws or whatever that may govern the development of these spaces in our capitalist society as the conflict may extend thanks to the different clashes of interests extended in time and within the interests of individuals. Then the idea of conflict in the artistic proposals discussed here becomes an act of deterritorialization and symbolic reterritorialization that is observed as inherent dynamics in the process of occupation of space-place by the artist. Somehow Orozco from the appropriation of existing spatiotemporal discourses produce what Deleuze and Guattari (1987) have termed a deterritorialization: Because the "absolute deterritorialization” doesn't exist if there is no a reinterpretation, a reconsideration of space-time, that is a symbolic reterritorialization.

\section{Acknowledgements}

This paper is included in the whole of the research proposed by the research project: "Temporal image: heterochrony and anachronism in contemporary visual culture”, HAR-ref. 2012-39322. The paper is funded under the program of the "Dirección General de Investigación y Gestión del Plan Nacional I + D + I de Proyectos de Investigación del Ministerio de Economía y Competitividad” of the Government of Spain.

\section{References}

Appadurai, A. (2001). La modernidad desbordada. Dimensiones culturales de la globalización. Montevideo: Ediciones Trilice y Fondo de Cultura Económica.

Bhabha, H. (2014). El compromiso de la teoría. Revista Acción Paralela. http://www.accpar.org/numero4/bhabha.htm

Bois, Y.-A. et al. (2007). Gabriel Orozco. Madrid: Ed. Turner.

Bonami, F. (2014). Gabriel Orozco es un extremista clásico.

http://www.francia.org.mx/debate/diciembre/gabriel_orozco.htm

Critchley, S. (2010). The Infinite Demand of Art. Art \& Research A Journal of Ideas Contexts and Methods, 3, 1-14.

Deleuze, G., \& Guattari, P. F. (1987). A Thousand Plateaus: Capitalism and Schizophrenia. Minneapolis: University of 
Minnesota Press.

García Canclini, N. (1997). Cultura y comunicación: Entre lo global y lo local. Buenos Aires: Ediciones de periodismo y comunicación.

Harvey, D. (1989). The Condition of Postmodernity: An Enquiry into the Origins of Cultural Change. London: Wiley.

Huyssen, A. (2002). En busca del futuro perdido. Cultura y memoria en tiempos de globaIización. México: Fondo de Cultura Económica.

Okwui, E. (1997). Gabriel Orozco, Silencios infinitos. Atlántica, Summer. 
Scientific Research Publishing (SCIRP) is one of the largest Open Access journal publishers. It is currently publishing more than 200 open access, online, peer-reviewed journals covering a wide range of academic disciplines. SCIRP serves the worldwide academic communities and contributes to the progress and application of science with its publication.

Other selected journals from SCIRP are listed as below. Submit your manuscript to us via either submit@scirp.org or Online Submission Portal.
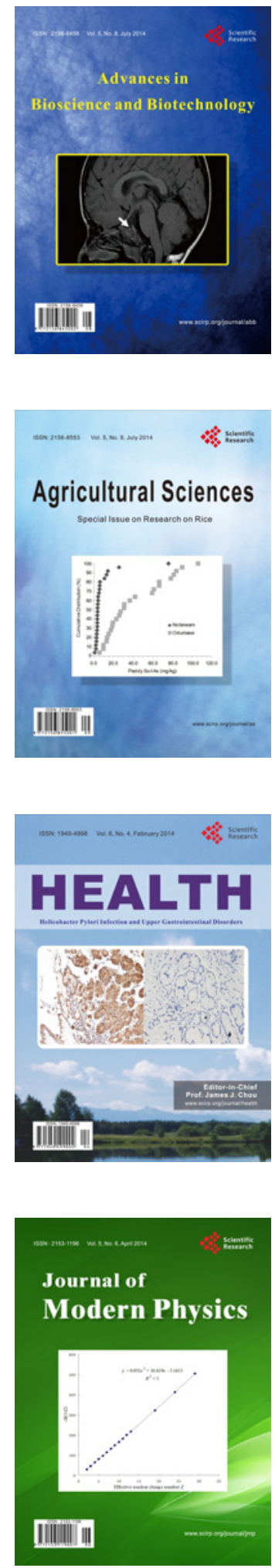
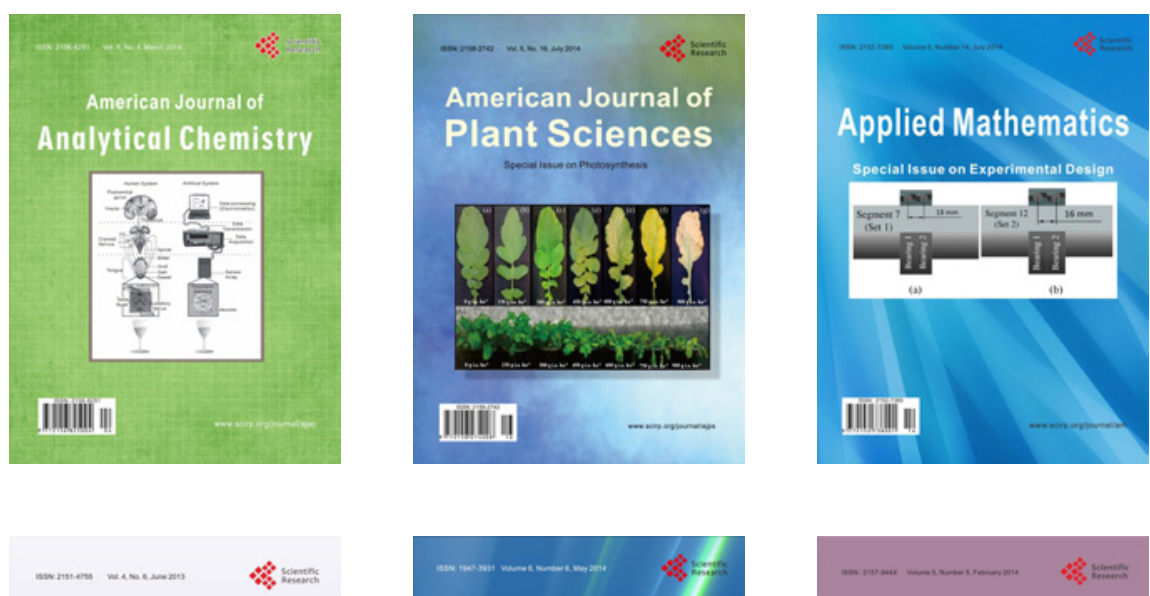

Creative Education
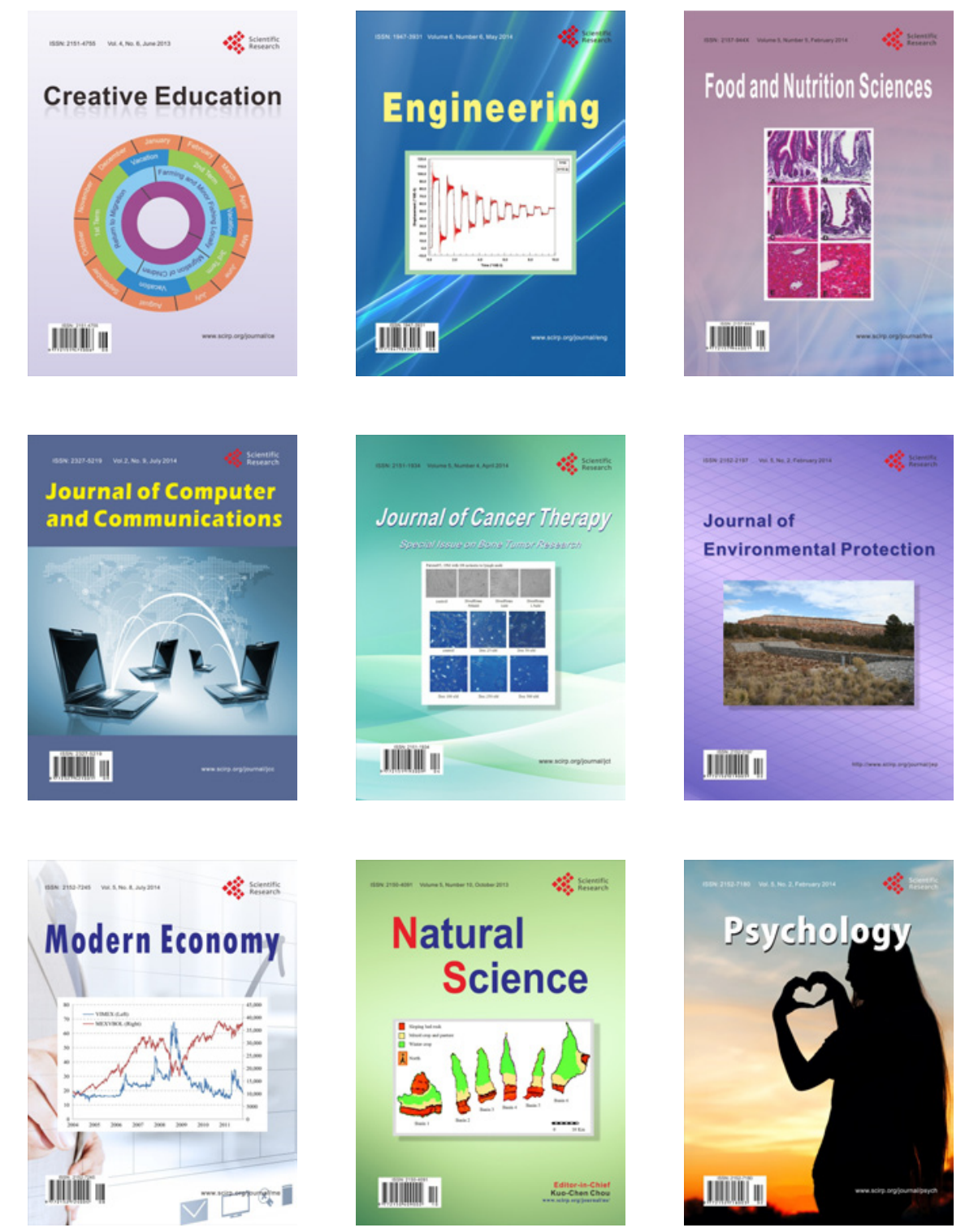